\title{
ОГРАНИЧЕНИЕ ЛИЧНЫХ НЕИМУЩЕСТВЕННЫХ ПРАВ ГРАЖДАН В ЦЕЛЯХ ОБЕСПЕЧЕНИЯ БИОЛОГИЧЕСКОЙ БЕЗОПАСНОСТИ: СОЧЕТАНИЕ ЧАСТНЫХ И ПУБЛИЧНЫХ ИНТЕРЕСОВ
}

\section{LIMITING CITIZENS 'PERSONAL NON-PROPERTY RIGHTS FOR BIOLOGICAL SECURITY: A COMBINATION OF PRIVATE AND PUBLIC INTERESTS}

A. Valevskaya

Summary. The article is devoted to the issues of biosafety and the position of the legislator on the possibility of restricting for this purpose the personal non-property rights of citizens and combining such restriction with the personal and public interests of the state. It is noted that limiting subjective civil rights as interference in private affairs and in the unhindered exercise of rights is possible as an exception to the general rule on the exercise of civil rights by virtue of personal discretion. The article states that the key component of such restriction is the inadmissibility of arbitrary prohibition, which is based on the requirement that the rights of citizens cannot be diminished (art. 55, para. 2, of the Constitution of the Russian Federation), on the leading normative legal acts.

Keywords: biological safety, personal non-property rights, personal interests, public interests, restriction, freedom of movement, choice of place of residence and residence.
4 еловеческое общество и государство прошли достаточно длительный исторический путь, чтобы прийти к осознанию и к воплощению в реальную жизнь принципа первостепенного значения личных неимущественных прав граждан. Ценность любой правовой системы определяется именно той ролью, какая отводится фундаментальным основам, на которых базируются личные неимущественные права и обеспечиваются интересы индивида в корреляции с публичными интересами. Законодатель при этом не вмешивается в содержание всех без исключения личных неимущественных прав, а призван обозначить внешние границы их осуществления, регламентируя ряд наиболее важных аспектов, включая ограничения в сфере биологической безопасности, которая охватывает значительную область санитарно-эпидемиологического состояния, смежные сферы ветеринарно-санитарного, а также фитосанитарного контроля, экологической безопасности, среды обитания и используется при имеющих большое значение мероприятиях по предупреждению и ликвида-
Валевская Ангелина Анатольевна

К.ю.н., дочент, ФГБОУ ВО «Саратовская государственная юридическая академия» a.valevskaya@yandex.ru

Аннотация. Статья посвящена вопросам биологической безопасности и позиции законодателя относительно возможности ограничения с указанной целью личных неимущественных прав граждан и сочетания подобного ограничения с личными и публичными интересами государства. Отмечено, что ограничение субъективных гражданских прав, как вмешательство в частные дела и в беспрепятственное осуществление прав, представляется возможным в качестве исключения из общего правила об осуществлении гражданских прав в силу личного усмотрения. В статье указано, что ключевой составляющей подобного ограничения выступает недопустимость произвольного запрета, что основано на требовании о невозможности умаления прав граждан (ч. 2 ст. 55 Конституции РФ), на ведущих нормативных правовых актах.

Ключевые слова: биологическая безопасность, личные неимущественные права, личные интересы, публичные интересы, ограничение, свобода передвижения, выбор места пребывания и жительства.

ции чрезвычайных ситуаций биологического характера $[1$, c. 6].

Вопросы обеспечения безопасности волнуют человечество на протяжении всех этапов цивилизационного развития. После двух мировых войн и прекращения режима «холодной войны» не оправдали себя надежды относительно уменьшения количества угроз международной и национальной безопасности, к числу которой относится биологическая безопасность. Межгосударственные и национальные конфликты, террористические акты, угроза ядерной войны, многочисленные чрезвычайные ситуации техногенного и природного характера продолжают представлять особую опасность и угрозу безопасности и в XXI в. [2, с. 49]. В связи с этим, политика безопасности государства и мирового сообщества, в целом, может быть определена в качестве особой деятельности по обеспечению международной, национальной и иных видов безопасности, а политика национальной безопасности в государственном масштабе 
должна развиваться, как во внешнегосударственном, так и в внутреннегосударственном масштабах [3, с. 62].

В современной России фундаментальные основы безопасности регламентированы в Конституции РФ [4] (п. 3 ст. 37, 98 и др.), в нормах Федерального закона от 28 декабря 2010 г. № 390-Ф3 «О безопасности» [5] и на уровне национальной стратегии государства. Так, на основании Указа Президента РФ от 31 декабря 2015 г. № 683 «О Стратегии национальной безопасности Российской Федерации» [6], национальная безопасность - состояние защищенности личности, общества и государства от внутренних и внешних угроз, при котором реализуются конституционные права и свободы, и которая включает оборону и все виды безопасности, охраняемые законодательством, - прежде всего, государственную, общественную, информационную, экологическую, экономическую, биологическую, энергетическую и безопасность личности.

На современном этапе российское государство уделяет особое внимание данной проблематике. Вопросы биологической безопасности, прав граждан в данной правовой плоскости, вопросам возможного ограничения личных неимущественных прав граждан нашли отражение в Указе Президента РФ от 11 марта 2019 г. № 97 «Об Основах государственной политики Российской Федерации в области обеспечения химической и биологической безопасности на период до 2025 года и дальнейшую перспективу» [7]. Указанным нормативным правовым актом в качестве ведущих биологических угроз современности признаны: модификация свойств, форм патогенных биологических агентов, переносчиков, мест обитания переносчиков в связи климатическими изменениями и в процессе природных катастроф; появление новых инфекций неизвестными патогенами; внесение редких либо прежде не имеющих место на российской территории инфекционных и паразитарных заболеваний, образование и распространение природно-очаговых инфекций, инфицированность новыми возбудителями, возврат исчезнувших инфекций, аварии на объектах с источниками биологической опасности, диверсии, террористические акты на подобных объектах и связанные с применением опасных биологических веществ, др.

В Проекте Федерального закона № 850485-7 «О биологической безопасности Российской Федерации» [8] от 2 декабря 2019 г. биологическая безопасность определяется как состояние защищенности населения и окружающей среды от воздействия опасных биологических факторов, при котором обеспечивается допустимый уровень биологического риска. Закон принят в первом чтении 22 января 2020 г. и вступил в юридическую силу с 31 марта 2020 г. Как отмечено в Пояснительной записке к Проекту закона «О биологической безопасности
Российской Федерации», на современном этапе отмечается увеличение существующих прежде и появление новых биологических угроз, что потребовало создание обновленных межотраслевых подходов, нормативной регламентации для формирования и функционирования необходимой эффективной системы обеспечения биологической безопасности.

Данный закон,- отметил заместитель председателя профильного комитета Государственной Думы РФ по охране здоровья Леонид Огуль,- закон о существовании человека, который непосредственно касается многих сфер жизни и выступит истоком создания в России комплексной правовой и иной защиты граждан от биологических и химических угроз современной цивилизации. Речь идет не только о защите от болезней, эпидемий, но и о бесконтрольном использовании лекарственных препаратов, способствующих возникновению нечувствительности человека к антибиотикам [9]. В указанной связи, ограничение прав граждан на свободное потребление антибиотиков выступит определенным ограничением личного неимущественного права на здоровье, т.е. на свободу осуществлять лечение абсолютно самостоятельно, однако признан прогрессивной мерой, обеспечивающей охрану здоровья и жизни, в целом.

Новый закон восполняет правовой пробел также о биологических угрозах террористического характера. Данный вопрос чрезвычайно важен, поскольку на территории России в 2019 г. располагается 73 особо радиационно опасных и ядерно-опасных объектов, представляющих химическую и биологическую опасность, в т.ч. в отношении хранения образцов небезопасных для жизни и здоровья человека вирусов, вызывающих эпидемии [10]. Перечень объектов не является исчерпывающим: в России эксплуатацию радиационно опасных и ядерно-опасных производств и объектов осуществляют многочисленные воинские части и организации Вооруженных Сил РФ, имеющие ядерные боеприпасы, ядерные энергетические и ядерные исследовательские установки. Биологическую угрозу России представляют также бесконтрольные археологические и палеонтологические раскопки, в результате которых обнаруженные объекты могут включать биологически-опасные фактоpы.

В сложившейся ситуации необходимо особое внимание к вопросам нарушения специальных правил безопасности, биологической, экологической безопасности как со стороны законодателя, правоприменителя, так и в научных кругах, занимающихся научными исследованиями в данной сфере. Новые позиции государства должны принимать во внимание, что обеспечение безопасного обращения с объектами и источниками по- 
вышенной опасности напрямую зависит от соблюдения специально установленных требований и правил, нарушение которых приводит к жертвам, биологическим и экологическим катастрофам, к человеческим трагедиям.

Фундаментальная основа возможных ограничений личных неимущественных прав граждан в целях обеспечения биологической безопасности заложена в гл. 2 Конституции РФ и развита в ст. 22 ГК РФ [11]: никто не может быть ограничен в правоспособности и дееспособности иначе, как в случаях и в порядке, установленных законом. Комплекс личных гражданских прав, по поводу которых возникают личные неимущественные права, неимущественные отношения граждан, представлен В ст. 150 ГК РФ: жизнь и здоровье, достоинство, личная неприкосновенность, честь, доброе имя, деловая репутация, неприкосновенность частной жизни и жилища, личная, семейная тайна, свобода передвижения, свобода выбора места пребывания и жительства, имя, авторство, иные нематериальные блага, которые принадлежат от рождения, в силу закона, неотчуждаемы и непередаваемы иным способом.

Несмотря на тот факт, что регламентация системы личных неимущественных прав позволяет гражданам в силу личного усмотрения и волеизъявления определять собственное поведение в сфере частной и общественной жизни, гражданин пребывает в неизолированном обществе, является членом социума, а его личные интересы должны коррелировать с публичными интересами. Подобная корреляция присутствует во многих сферах жизнедеятельности, включая сферу обеспечения биологической безопасности. При этом особое значение имеет тот факт, что ограничение субъективных гражданских прав, как вмешательство в частные дела и в беспрепятственное осуществление возможно как исключение из общего правила о свободном осуществлении. Ключевой составляющей ограничения выступает недопустимость произвольного запрета, невозможность умаления прав граждан [12, с. 7].

В Федеральном законе «О биологической безопасности Российской Федерации» [13], вступившем в силу 31 марта 2020 года, в целях исключения биологических рисков, как вероятности причинения вреда (с учетом тяжести) здоровью человека, животным, растениям и (или) окружающей среде в результате воздействия опасных биологических факторов, особое внимание уделено правам, обязанностям граждан и публичных органов власти, т.е. корреляции частных и публичных интересов. Подобная корреляция в области обеспечения биологической безопасности проявляется в сочетании интересов и юридической ответственности, как личности, общества, так и российского государства.
К обязанностям граждан в сфере обеспечения биологической безопасности закон относит: соблюдение норм действующего законодательства в данной сфере, требований, предусмотренных законодательством в области охраны окружающей среды, охраны здоровья граждан, обеспечения санитарно-эпидемиологического благополучия, ветеринарной безопасности, в сфере обеспечения карантина растений, в генно-инженерной сфере деятельности, в области безопасности продукции. К обязанностям граждан по обеспечению биологической безопасности относится также реализация необходимых мер, которые исключают нарушение прав на охрану здоровья и окружающей среды от небезопасных биологических факторов (угроз).

Основной концепций российского законодательства в данном направлении признано следующее: в случае допустимости ограничения предусмотренных законом прав государство обязано применять исключительно необходимые, но не чрезмерные ограничительные меры. Подобные изъятия могут быть оправданы публичными интересами, предусмотренными в ст. 55 (ч. 3) Конституции РФ. При этом, ограничения должны отвечать принципам справедливости, выступать в качестве адекватных публичных мер, являться соразмерными и пропорциональными. Ограничительные меры при этом не сопоставляются с существом конституционного строя, не ограничивают основное содержание конституционных норм о правах и свободах граждан.

С учетом вышеизложенного, российское законодательство направлено не только на обеспечение биологической безопасности граждан, но и на защиту неотъемлемых неимущественных прав, принадлежащих индивиду от рождения.

В соответствии с действующим российским законодательством, в целях обеспечения биологической безопасности, возможным ограничениям могут подвергаться такие личные неимущественные права, как право на неприкосновенность жилища, свободу передвижения, выбор места пребывания и жительства. В отношении ограничения выезда за границу по подобным основаниям, в соответствии с нормами Федерального закона от 15 сентября 1996 г. № 114-Ф3 «О порядке выезда из Российской Федерации и въезда в Российскую Федерацию» [14], в ситуации констатации факта наличия на территории иностранного государства чрезвычайной ситуации, связанной с угрозами безопасности, включая экономическую, биологическую безопасность, Правительством РФ могут быть предприняты меры по формированию для граждан рекомендаций о нежелательности въезда в определенное государство. Подобные рекомендации не признаны, однако, основанием для временного ограничения права на выезд из Российской 
Федерации, т.е. непосредственного ограничения личного неимущественного права на свободу передвижения.

Закон № 5242-1 «О праве граждан Российской Федерации на свободу передвижения, выбор места пребывания и жительства в пределах Российской Федерации» [15] в ст. 1 предусматривает, что ограничение права граждан на свободу передвижения, выбор места пребывания и жительства в пределах территории российского государства допускается исключительно в силу акта федерального законодательства. Вышеизложенное коррелирует ведущим международным документам (Всеобщая декларация прав человека 1948 г. [16], Международный пакт о гражданских и политических правах 1966 г. [17] и другие международные акты) и российским нормативным правовым актам.

На основании ч. 3 ст. 55 Конституции РФ, ограничение права на свободу личного передвижения, избрание места пребывания и жительства на территории России может быть установлено для российских граждан, в отношении иностранных граждан, а также - лиц без гражданства. Подобные ограничения могут касаться, в частности, зон экологического бедствия, территорий и мест, В которых при наличии угрозы распространения массовых заболеваний (инфекционных, неинфекционных), отравлений введены условия и режимы особого характера проживания, экономической деятельности. Совокупность подобных территорий Российской Федерации составляют территориальные зоны, в которых введено военное и чрезвычайное положение.

Гуманистическая направленность российской Конституции, соответственно, заключается в коррективах правоотношений человека и государства: государство вправе регулировать поведение человека исключительно с целью обеспечения соблюдения сбалансированных личных, публичных и иных значимых для государства и личности интересов.

На основании Федерального конституционного закона от 30 мая 2001 г. № 3-ФКЗ «О чрезвычайном положении» [18], чрезвычайное положение представляет собой временную государственную меру, применяемую государством. Введение чрезвычайного положения представляется возможным исключительно в целях обеспечения безопасности граждан, защиты конституционного строя, в частности, в связи с чрезвычайными ситуациями природного, техногенного характера, экологическими ситуациями, включая эпидемии, эпизоотии, образовавшиеся в результате аварий, катастроф, различных небезопасных природных катаклизмов (стихийных бедствий и пр.), которые повлекли либо могут способствовать человеческим жертвам, возникновению ущерба здоровью и вреда окружающей природной среде, другим потерям в сфере нормальной жизнедеятельности граждан.

В подобных чрезвычайных ситуациях, в соответствии со ст. 11 (п. «б») Федерального конституционного закона от 30 мая 2001 г. № 3-ФК3 «О чрезвычайном положении», в целях публичных и личных интересов, ограничение такого личного неимущественного права граждан, как свобода передвижения, выбор места пребывания и жительства, может проявляться в форме ограничений на свободу передвижения, особого режима въезда и выезда, в т.ч. ограничения на въезд, на пребывание на данной территории иностранных граждан и лиц без гражданства. Как отмечено в ст. 12 (п. «а») Закона, органы государства вправе осуществить временное отселение граждан в безопасные территории, однако, с гарантированным предоставлением стационарных, временных жилых объектов; ввести комендантский час, как запрет в определенное время суток находиться в общественных местах без наличия разрешения и иных специальных документов (п. «а» ст. 13).

Поскольку свобода передвижения - такая же естественная потребность человека, как свобода труда и творчества, в целом, - как свобода в классическом понимании [19, с. 115], законодательство в сфере подобного ограничения должно отражать демократические ценности российского государства, не нарушать иных личных неимущественных и имущественных прав граждан, сочетать личные и публичные интересы, что свойственно правовому государству.

Верховный Суд РФ отметил: под публичными интересами следует понимать, в частности, интересы неопределенного круга лиц, направленные на обеспечение безопасности жизни и здоровья граждан, а также обороны и безопасности государства, охраны окружающей природной среды [20].

Соответственно, вынужденные ограничения личных неимущественных прав граждан в целях обеспечения биологической безопасности, представляя собой несомненное вмешательство в частные дела и в беспрепятственное осуществление гражданских прав, выступает в качестве исключения из общего правила. Подобное ограничение должно являться правомерным и основанном на законе, базироваться на Конституции РФ и международно-правовых актах. Правовой основой ограничения прав граждан в целях обеспечения биологической безопасности выступает п. 3 ст. 55 Конституции РФ: «Права и свободы человека и гражданина могут быть ограничены федеральным законом только в той мере, в какой это необходимо в целях защиты основ конституционного строя, нравственности, здоровья, прав и законных интересов 
других лиц, обеспечения обороны страны и безопасности государства».

Конституционный суд РФ указал, что ограничение прав и свобод граждан должны являться необходимыми и быть пропорциональными конституционно признанным публичным целям, т.е. государство призвано использовать исключительно вынужденные и обусловленные подобным целям необходимые меры [21]. Соответственно, при ограничении личных неимущественных прав граждан в целях обеспечения биологической безопасности особое внимание должно быть уделено корреляции конституционно значимых целей с балансом интересов отдельной личности и публичных интересов государства в целом. Эффективная работа по обеспечению национальной биологической безопасности должна учитывать не только организационные моменты по взаимодействию между различными надзорными органами и интеграцию данных различных систем сбора информации. Влияние на уязвимость общества перед биологическими угрозами во многом определяется дру- гими фундаментальными основами - позицией самого гражданина, который, подвергаясь ограничениям личных неимущественных прав в связи с необходимостью обеспечения биологической безопасности, не рассматривает подобные ограничения, как ограничение правосубъектности, а оказывает содействие в обеспечении безопасности, предпринимает меры профилактики.

По результатам социологического опроса, проведенного рейтинговым агентством DataLight в 2018 г., в качестве основных составляющих обеспечения национальной безопасности, структурированных по уровню значимости для России, выступают: обеспечение техногенной, экологической и биологической безопасности - 88\%; охрана общественного порядка - 6\%; защита от угроз стихийных бедствий - 37\%; защита государственного строя - 18\%; защита общественного строя $11 \%$; обеспечение территориальной неприкосновенности - 18\%; обеспечение политической и экономической независимости нации - 17\%; обеспечение здоровья нации - 7\%; борьба с преступностью - 8\% [22].

\section{ЛИТЕРАТУРА}

1. Гущин В.А., Мануйлов В. А., Макаров В. В., Ткачук А. П. Знадлежащая организация системы биобезопасности как средство снижения уязвимости общества, экономики и государства перед биогенными угрозами // Вестник РГМУ.—2018. - C. 6.

2. Насакина Л. Н. Национальная безопасность России и пути ее укрепления // Научный журнал «Дискурс» — 2017.— № 2 (4). — С. 49.

3. Кулаков, В.0 глобальной конкурентоспособности России / В. Кулаков, 3. Алиев // Власть. - 2010.—№ 5.— С. 60-63.

4. Конституция Российской Федерации (принята всенародным голосованием 12.12.1993) (с учетом поправок, внесенных Законами РФ о поправках к Конституции РФ от 30.12.2008 № 6-ФК3, от 30.12.2008 № 7-ФК3, от 05.02.2014 № 2-ФК3, от 21.07.2014 № 11-ФК3) // Российская газета.— 1993.—25 декабря.

5. Федеральный закон от 28 декабря 2010 г. № 390-Ф3 (ред. от 05.10.2015) «0 безопасности» // Собрание законодательства Российской Федерации. — 2011. -№ 1. -Ст. 2.

6. Указ Президента Российской Федерации от 31 декабря 2015 г. № 683 «0 Стратегии национальной безопасности Российской Федерации» // Собрание законодательства Российской Федерации.—-2016. -№ 1 (часть II). -Ст. 212.

7. Указ Президента РФ от 11 марта 2019 г. № 97 «06 Основах государственной политики Российской Федерации в области обеспечения химической и биологической безопасности на период до 2025 года и дальнейшую перспективу» [Электронный ресурc] URL: http://base.consultant.ru/cons/cgi/online. cgi?req=doc. - (дата обращения 16.04.2020).

8. Проект Федерального закона № 850485-7 «0 биологической безопасности Российской Федерации» (ред., внесенная в ГД ФС РФ, текст по состоянию на 02.12.2019) [Электронный ресурc] URL: https://sozd.duma.gov.ru/ (дата обращения 16.04.2020).

9. Госдума приняла в I чтении законопроект о биологической безопасности России [Электронный ресурс] URL: https://tass.ru/obschestvo/7570229 (дата 06ращения 16.04.2020).

10. Распоряжение Правительства Российской Федерации от 14 сентября 2009 г. № 1311-р (в ред. от 30.09.2018) «06 утверждении перечня организаций, эксплуатирующих особо радиационно опасные и ядерно- опасные производства и объекты» [Электронный ресурc] URL: http://base.consultant.ru/cons/cgi/ online.cgi?req=doc. - (дата обращения 16.04.2020).

11. Гражданский кодекс Российской Федерации. Часть первая от 30 ноября 1994 г. № $51-Ф 3$ (ред. от 01.01.2020) // Собрание законодательства Российской Федерации. - 1994.— № 32. Ст. 3301.

12. Захаров Н. О. Субъективные гражданские права и свободы и регулирование их ограничение / Адвокат.— 2016.— № 1.—C. 7.

13. Проект Федерального закона № 850485-7 «0 биологической безопасности Российской Федерации» (ред., внесенная в ГД ФС РФ, текст по состоянию на 02.12.2019) [Электронный ресурc] URL: https://sozd.duma.gov.ru/ (дата обращения 16.04.2020).

14. Федеральный закон от 15 сентября 1996 г. № 114-Ф3 «0 порядке выезда из Российской Федерации и въезда в Российскую Федерацию» (ред. от 16.12.2019) // Собрание законодательства Российской Федерации. - 1996. -№ 34. -Ст. 4029.

15. Закон РФ от 25 июня 1993 г. № 5242-1 (ред. от 01.04.2019) «0 праве граждан Российской Федерации на свободу передвижения, выбор места пребывания и жительства в пределах Российской Федерации» // «Российская газета.— 1993.— № 152.

16. Всеобщая декларация прав человека от 10 декабря 1948 г. // Ведомости Верховного Совета СССР.—1976. -№ 17. -Ст.291. 
17. Международный Пакт о гражданских и политических правах Организации Объединенных Наций от 19 декабря 1966 г. // Ведомости Верховного Совета СССР.-1976. -№ 17. Ст. 291.

18. Федеральный конституционный закон от 30 мая 2001 г. № 3-ФКЗ (ред. от 03.07.2016) «0 чрезвычайном положении» // Собрание законодательства Российской Федерации.—2001.— № 23.—- С. 2277.

19. Кинжибеков В. В. Ограничение прав граждан России на выезд за пределы РФ // Молодой ученый. — 2020. — № 2. — C. $115-117$.

20. Постановление Пленума Верховного Суда Российской Федерации от 23 июня 2015 г. № 25 [Электронный pecypc] URL: http://base.consultant.ru/cons/cgi/ online.cgi?req=doc. - (дата обращения 16.04.2020).

21. Постановление Конституционного суда Российской Федерации от 13 июня 1996 г. № 14-П «По делу о проверке конституционности части пятой статьи 97 Уголовно-процессуального кодекса РСФСР в Связи с жалобой гражданина В. В. Щелухина» // Вестник Конституционного суда РФ. 1996. № 4.

22. Результаты опроса, проведенного рейтинговым агентством DataLight в 2018 г. // Сайт рейтингового агентства DataLight [Электронный ресурс] — Pежим доступа URL: https://datalight.me/ (дата обращения 16.04.2020).

( ) Валевская Ангелина Анатольевна ( a.valevskaya@yandex.ru).

Журнал «Современная наука: актуальные проблемы теории и практики»

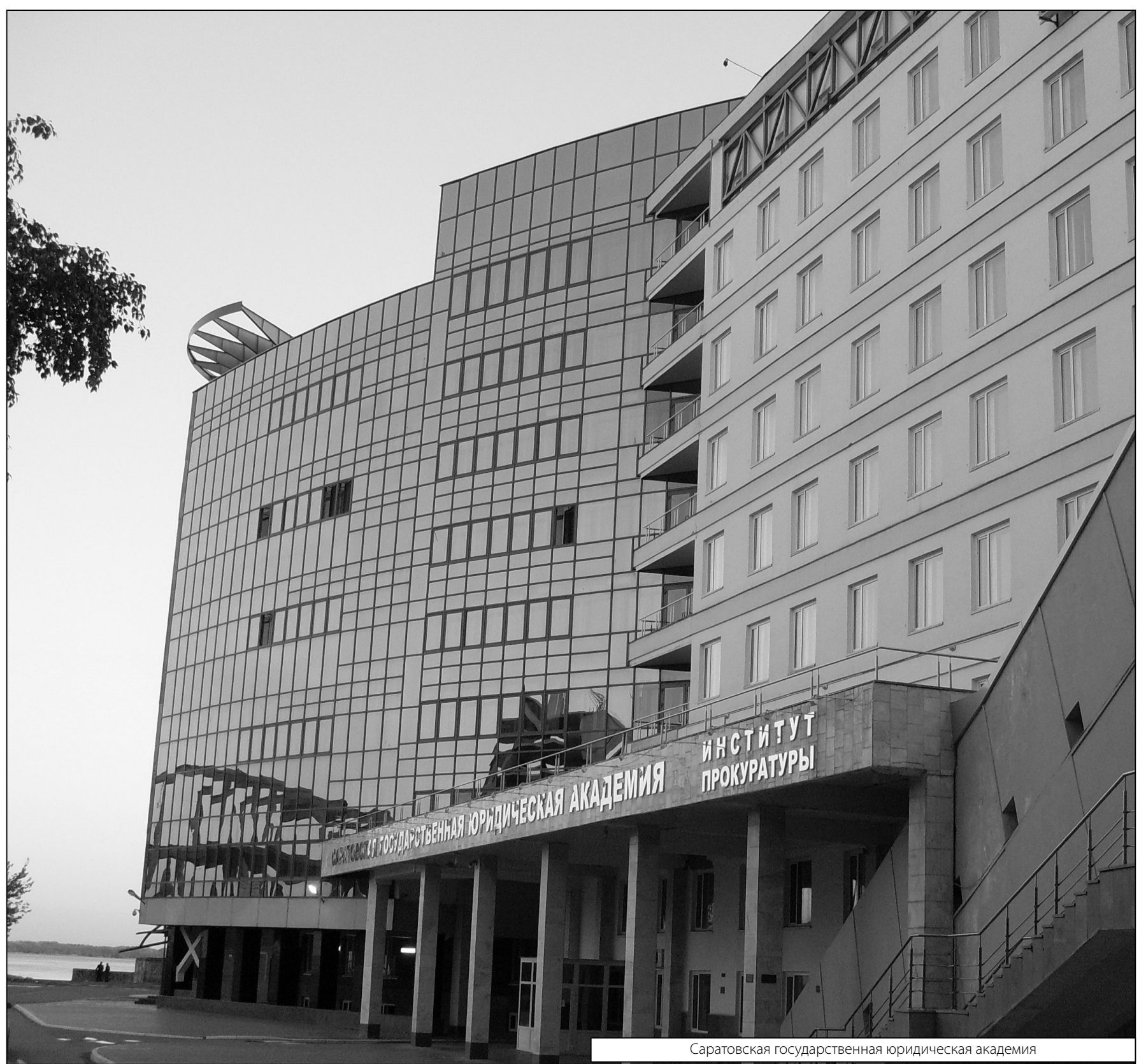

